Protocols

\title{
Synergistically enhanced stability of laccase immobilized on synthesized silver nanoparticles with water-soluble polymers
}

\author{
M.N.M. Cunha ${ }^{a}$, H.P. Felgueiras ${ }^{\mathrm{a}, *}{ }^{\text {I. }}$ Gouveia ${ }^{\mathrm{b}}$, A. Zille ${ }^{\mathrm{a}}$ \\ a 2C2T, Centre for Science and Textile Technology, Department of Textile Engineering, University of Minho, Campus of Azurém, 4800-058 Guimarães, \\ Portugal \\ ${ }^{\mathrm{b}}$ University of Beira Interior, FibEnTech, Fiber Materials and Environmental Technologies-RED Unit, Covilhã, Portugal
}

\section{A R T I C L E I N F O}

\section{Article history:}

Received 20 October 2016

Received in revised form 6 March 2017

Accepted 9 March 2017

Available online 12 March 2017

\section{Keywords:}

Silver nanoparticles

Polymer stabilizer

Laccase

Synergistic effect

Enzymatic stability

\begin{abstract}
A B S T R A C T
Silver nanoparticles (AgNPs) were synthesized by citrate reduction method in the presence of polymers, poly(ethylene glycol) (PEG), poly(vinyl alcohol) (PVA) and chitosan, used as stabilizing agents, and an oxidoreductase enzyme, laccase (Lac), with the goal of expanding the NPs antimicrobial action.

AgNPs were characterized by UV-vis spectrometry, dynamic light scattering and transmission electron microscopy. As protecting agents, PEG and PVA promoted the formation of spherical uniformly-shaped, small-sized, monodispersed AgNPs $(\approx 20 \mathrm{~nm})$. High Mw polymers were established as most effective in producing small-sized NPs. Chitosan's viscosity led to the formation of aggregates. Despite the decrease in Lac activity registered for the hybrid formulation, AgNPs-polymer-Lac, a significant augment in stability over time (up to 13 days, at $50^{\circ} \mathrm{C}$ ) was observed. This novel formulation displays improved synergistic performance over AgNPs-Lac or polymer-Lac conjugates, since in the former the Lac activity becomes residual at the end of 3 days. By enabling many ionic interactions, chitosan restricted the mass transfer between Lac and substrate and, thus, inhibited the enzymatic activity.

These hybrid nanocomposites made up of inorganic NPs, organic polymers and immobilized antimicrobial oxidoreductive enzymes represent a new class of materials with improved synergistic performance. Moreover, the Lac and the AgNPs different antimicrobial action, both in time and mechanism, may also constitute a new alternative to reduce the probability of developing resistance-associated mutations.
\end{abstract}

(c) 2017 Elsevier B.V. All rights reserved.

\section{Introduction}

Silver nanoparticles (AgNPs) display unique optical, electrical and thermal properties, making them exceptional agents to be incorporated into products of electrical, textile, cosmetic, biological or even medical uses [1-3]. Since the $20^{\text {th }}$ century, AgNPs have been used in the biomedical field as antimicrobial agents [4]. AgNPs act effectively in the microorganism metabolism by attaching to the cell membrane and drastically disrupting its proper functions, such as permeability and respiration. Recent studies suggest the primary mechanism of antibacterial action of AgNPs to be the release of silver ions $\left(\mathrm{Ag}^{+}\right)$[5]. $\mathrm{Ag}^{+}$ions can interact with the thiol groups of vital enzymes inactivating them and, ultimately, affecting the ability of the cell's DNA to replicate [6]. AgNPs possess remarkable antiseptic properties, broad range of activity against bacteria (gram-negative and gram-positive), fungi and virus, are bactero-

\footnotetext{
* Corresponding author.

E-mail address: helena.felgueiras@2c2t.uminho.pt (H.P. Felgueiras).
}

static (growth inhibition) and bactericidal, are biocompatible and, at low concentrations, are harmless to the human cells [3,7]. In comparison to other antibiotics, bacterial resistant to AgNPs has been observed only rarely and does not constitute a complication [4]. In addition, several new and cheaper methods to produce AgNPs have been developed in the last years, which is of great importance for large scale production [3,7].

The AgNPs antimicrobial nature is described as size- and shapedependent. It has been established that smaller NPs display better antimicrobial activity as they can penetrate easily the cell membrane and reach the nuclear content [6,8]. Concerning shape, although truncated-triangular-shaped NPs have been reported as the most bactericidal [9], spherical NPs remain the best suited for practical applications in either colloidal form or immobilized state $[10,11]$. Many methods, chemical, physical, photochemical and biological, have been used to synthesize AgNPs with controlled size, shape, distribution and stability [12]. Chemical methods are perhaps the most commonly used, as they provide a simple way to synthesize AgNPs in solution. Generally, the chemical synthesis of AgNPs requires three main components: a metal precursor, a reduc- 
ing agent and a stabilizing agent [3]. The reducing agent reduces $\mathrm{Ag}^{+}$and promotes the formation of metallic silver $\left(\mathrm{Ag}^{0}\right)$. This is followed by agglomeration into oligomeric clusters that eventually generate colloidal AgNPs. To stabilize the dispersive NPs, prevent aggregation or binding, sedimentation and loss of surface properties, a stabilizing agent is added during AgNPs production [12]. For many years, organic and inorganic compounds, like citrates or surfactants, were used to stabilize the dispersive nature of AgNPs. However, problems with cost, scalability, control of particle size, size distribution and/or particle aggregation were very difficult to solve [13]. Recently, polymers such as poly(ethylene glycol) (PEG) or poly(vinyl alcohol) (PVA) have been recognized as effective stabilizing agents by implementing a protection mechanism based on steric repulsion. A balance is established between attractive and repulsive forces that depend on the polymer's chain length and adsorption mode $[4,14,15]$. These polymers govern not only the NPs size but also their surface charge and biological responses, including adsorption, distribution, metabolism, and excretion of the NPs $[12,16]$. Natural origin polymers like chitosan, which exhibit better biocompatibility than the synthetic referred, have been used as well $[17,18]$.

In the present study, the stability of AgNPs produced by chemical reduction method using PEG, PVA and chitosan as stabilizers was followed. The polymers were applied at different molecular weights (Mw) and concentrations, and their influence on the AgNPs size, shape and distribution (formation of aggregates) was established. Stabilizing AgNPs with water soluble polymers is very useful to improve the dispersion stability and antimicrobial performance of the NPs $[19,20]$. Also, since AgNPs is cytotoxic and genotoxic in high concentrations, it is important to fabricate antibacterial surfaces with controlled release of $\mathrm{Ag}^{+}$. Systems prepared with polymeric matrices can prevent the direct contact of AgNPs with the skin and allow a precise and local release of $\mathrm{Ag}^{+}$[21].

To enhance AgNPs antimicrobial action and safety, an oxidoreductase enzyme, laccase (Lac), was also combined with the polymer-stabilized AgNPs. Lac is a multicopper oxidase enzyme with great, but little explored, potential as a therapeutic agent in the fight against microbial organisms and biofilm formation, mainly due to its unique specificity, high activity and selectivity [22]. Lac is known to catalyze reactions that lead to the generation of antimicrobial species in the presence of mediators, oxyacids, phenols, iodine, and bromine [23,24]. Direct antimicrobial activity of crude Lac has been observed and primarily attributed to the electrochemical mode of action, which consists in penetrating the cell wall of the microorganisms, thereby causing leakage of essential metabolites and physically disrupting other microbial key cell functions [25-27]. The major limitations of using enzymes as therapeutic agents are the inability of keeping them active, their rapid elimination, low concentration at site and availability [28]. Immobilizing Lac on a carrier is likely to solve all these problems [29]. There have been many reports on the immobilization of Lac on a variety of support materials, including alginate beads [30], magnetic-chitosan [31], Amberlite [32], $\mathrm{SiO}_{2}$ nanocarriers [33] and various metallic NPs [34-36], to which Lac revealed great stability. However, none of those researches inferred about the indirect antimicrobial effect of Lac in presence of AgNPs and its potential to the biomedical field. In fact, very little research has been conducted on this subject. Lateef et al. has published one of the few studies in which the antimicrobial capacities of Lac immobilized onto AgNPs were assessed [37]. They reported effective inhibition against clinical isolates of Escherichia coli, Pseudomonas aeruginosa and Klebsiella pneumoniae. In a previous work, we have also shown the indirect antimicrobial effect of Lac immobilized onto bacterial nanocellulose against gram-positive (92\%) and gram-negative (26\%) bacteria and its acceptable cytotoxicity for wound dressing applications [38]. The effectiveness of Lac as antimicrobial relies on the oxidation of a substrate that is further transformed in an antimicrobial agent. Thus, an enhanced activity and stability in an immobilized enzyme is one of the most important features to be attained. The innovation behind this research focus on the combination of the Lac enzyme with polymer-stabilized AgNPs, which to the authors' knowledge has not yet been researched. The activity at different $\mathrm{pHs}$, temperatures and substrates, and the stability with time of the created complex were followed with the final goal of achieving improve performances. In this context, hybrid nanocomposites made up of inorganic NPs, organic polymers and immobilized antimicrobial enzymes represent a new class of materials [39,40]. These novel materials combine the benefits of enhanced antibacterial properties of polymer-stabilized NPs, that allow a better-controlled release of ions rather than the bulk material, with the safe and unspecific action of enzybiotics, and thus reducing the potential hazard influence of AgNPs in the human body [41,42].

\section{Materials and methods}

\subsection{Materials}

Silver nitrate $\left(\mathrm{AgNO}_{3}\right.$, Sigma), trisodium citrate $\left(\mathrm{Na}_{3} \mathrm{C}_{6} \mathrm{H}_{5} \mathrm{O}_{7}\right.$, Sigma) and sodium hydroxide ( $\mathrm{NaOH}$, Merck) were used in the production of the AgNPs. The synthesis of polymer-stabilized AgNPs was performed using PEG (Sigma), PVA (Sigma) or chitosan (Chitoclear ${ }^{\circledR}$, Primex, Iceland) at different molecular weights (Mw): PEG at Mw 1500 and 10,000, PVA at Mw 9000, 13,000, 31,000 and 85,000 , and chitosan at $800 \mathrm{Cps}(\sim 320 \mathrm{Mw})$ and 1600 Cps $(\sim 350 \mathrm{Mw})$. A commercial Lac (18g protein $\left.\mathrm{L}^{-1}\right)$ obtained from Myceliophthora thermophila (NS51003, Novozymes, Denmark, kindly supplied by Professor Moldes' research group from University of Vigo, Spain) was used as provided by the manufacturer. This enzyme was selected because of its well-established antimicrobial activity [43]. The activity of the enzyme Lac was tested against the substrates 2,2'-azino-bis(3-ethylbenzothiazoline-6sulphonic acid) (ABTS), 3,4-dimethoxyphenol (DMP) and catechol using the buffers citrate-phosphate (citric acid, $\mathrm{C}_{6} \mathrm{H}_{8} \mathrm{O}_{7}$ and disodium phosphate, $\left.\mathrm{Na}_{2} \mathrm{HPO}_{4} \cdot 7 \mathrm{H}_{2} \mathrm{O}\right)$, phosphate $\left(\mathrm{Na}_{2} \mathrm{HPO}_{4} \cdot 7 \mathrm{H}_{2} \mathrm{O}\right.$ and sodium phosphate monobasic, $\left.\mathrm{NaH}_{2} \mathrm{PO}_{4}\right)$ and carbonatebicarbonate (sodium carbonate anydrous, $\mathrm{Na}_{2} \mathrm{CO}_{3}$, and sodium bicarbonate, $\mathrm{NaHCO}_{3}$ ), all prepared with reagents from Sigma (the detailed buffers' composition is provided in Table S1 from the Supporting information). All water used was distilled $\left(\mathrm{dH}_{2} \mathrm{O}\right)$.

\subsection{Synthesis of AgNPs: bare and polymer-stabilized}

AgNPs colloidal dispersion, at an approximate concentration of $0.02 \mathrm{mg} \mathrm{L}^{-1}$, was synthesized in laboratory by a modified stepwise method of the conventional citrate reduction technique (also known as Turkevich method [44]), as previously described [45]. The above concentration was established for comparison purposes with the commercially available AgNPs (Sigma), which concentration is $0.02 \mathrm{mg} \mathrm{L}^{-1}$. For the entire process, the solutions were stirred at constant speed and the $\mathrm{pH}$ adjusted with $0.1 \mathrm{M}$ of $\mathrm{NaOH}$.

\subsubsection{Bare AgNPs}

A $100 \mathrm{~mL}$ of $1 \mathrm{mM} \mathrm{AgNO}_{3}$ was heated to boiling point in a $250 \mathrm{~mL}$ flask. To this solution, $10 \mathrm{~mL}$ of $1 \% \mathrm{Na}_{3} \mathrm{C}_{6} \mathrm{H}_{5} \mathrm{O}_{7}$ were added dropwise (3.8 $\mathrm{mM}$ final concentration). The $\mathrm{pH}$ of the solution was adjusted to 7.7 with nitric acid $\left(\mathrm{HNO}_{3}\right)$ or $\mathrm{NaOH}$. Because of evaporation, $\mathrm{dH}_{2} \mathrm{O}$ was added to restore the initial volume. The solution was heated again to boiling temperature until the colour changed (pale yellow). Then, it was removed from the heater and stirred until reaching room temperature (RT). The AgNPs were stored at $4{ }^{\circ} \mathrm{C}$ 
for $12 \mathrm{~h}$ prior to use to reduce the thermo-instability of the citrate emulsion.

\subsubsection{Polymer-stabilized: PVA, PEG and chitosan}

$1 \%, 3 \%$ and $5 \% \mathrm{~m} / \mathrm{v}$ solutions of PVA and PEG, at different $\mathrm{Mw}$, were prepared in $\mathrm{dH}_{2} \mathrm{O}$ and heated at $70-80^{\circ} \mathrm{C}$ for a complete homogenization. Each solution was combined at $90 / 10 \mathrm{v} / \mathrm{v}$ ratio with a $10 \mathrm{mM} \mathrm{AgNO}_{3}$ solution in $\mathrm{dH}_{2} \mathrm{O}(\mathrm{pH} 8)$, to a volume of $100 \mathrm{~mL}$. The mixture was heated until the boiling point was reached. $10 \mathrm{~mL}$ of $1 \% \mathrm{~m} / \mathrm{v} \mathrm{Na}{ }_{3} \mathrm{C}_{6} \mathrm{H}_{5} \mathrm{O}_{7}$ were added drop-by-drop. The solution was left to boil until the color changed. After, the heating was turned-off but the stirring was kept until the solution reached RT.

The first steps of the AgNPs synthesis in chitosan (deacetylation degree of $84.8 \pm 1.2 \%$ ) were equal to those described in the previous sub-chapter (Bare AgNPs): $1 \mathrm{mM} \mathrm{AgNO}_{3}$ was heated and $1 \%$ $\mathrm{Na}_{3} \mathrm{C}_{6} \mathrm{H}_{5} \mathrm{O}_{7}$ was added dropwise. Then, $1.14 \mathrm{~mL}$ of acetone were added to the mixture together with $0.5,0.75$ or $1 \mathrm{~g}$ of chitosan, repeated for each $\mathrm{Mw}$, to produce a $0.5 \%, 0.75 \%$ and $1 \%$ chitosan content in the AgNPs solution. The heating was kept until the chitosan was completely dissolved. The mixture was stirred until RT was reached.

\subsection{Spectrophotometric measurements}

UV-vis spectra of AgNPs synthesized in the presence or absence of polymers were acquired using a Unican UV-vis 2 equipment. Aliquots were collected from each mixture at different time points to test the AgNPs stability. They were diluted at $1: 2,1: 4$ or $1: 8$ when necessary to prevent deviation from Beer's Law linearity.

\subsection{Dynamic light scattering (DLS) and zeta potential measurements}

The AgNPs size distribution, polydispersity index and zeta potential were measured by dynamic light scattering (DLS) and electrophoretic light scattering (ELS) using a Zeta Sizer-Nano (Malvern Instruments). Data was collected after 30 scans at a constant temperature of $25 \pm 1^{\circ} \mathrm{C}$. Zeta potentials were measured in solution at a moderate electrolytic concentration. Each value was obtained by averaging measurements of three samples.

\subsection{Transmission electron microscopy (TEM)}

The AgNPs morphology was observed using a JEOL JEM 1400 transmission electron microscope (TEM, Japan) operating at $120 \mathrm{kV}$. NPs samples were submitted to glow discharged carbon-coated copper grids followed by negative staining with $1 \%(\mathrm{w} / \mathrm{v})$ uranyl acetate. This solution was used to improve AgNPs contrast and to easily visualize weaker electron contrast compounds, such as the used polymers and the degraded or transformed Ag species. Images were digitally recorded using a Gatan SC 1000 Orius CCD (USA) digital camera. Average NPs core diameter, size distributions and standard deviations (SD) were calculated for each NPs sample by applying Image J software analysis (developed at the National Institutes of Health, USA) to the collected TEM images.

\subsection{Lac immobilization on bare and polymer-Stabilized AgNPs}

Bare or polymer-stabilized AgNPs, at $0.02 \mathrm{mg} \mathrm{L}^{-1}$, were immobilized with Lac diluted 1:1000 in the appropriate buffer to a final protein concentration of $18 \mathrm{mg}$ protein $\mathrm{L}^{-1}$, by simple immersion for $15 \mathrm{~min}$ and RT, under stirring conditions. Prior to enzyme activity measures the non-immobilized Lac was removed from solution by centrifugation for $5 \mathrm{~min}$ at $10,000 \mathrm{rpm}$ (Eppendorf, Centrifuge 5415 D) and re-suspended in the appropriate buffer (citrate-phosphate at $\mathrm{pH} 3$ for ABTS and $\mathrm{pH} 6$ for DMP). The theoretical ratio between Lac and NPs was estimated as $\approx 0.9 \mathrm{~g}$ of Lac per mg of AgNPs.

\subsection{Enzymatic activity}

Lac activity, relative and specific, was determined by measuring the slope of the initial linear portion of the kinetic curve using ABTS, DMP and catechol as substrates at the temperature of $50^{\circ} \mathrm{C}$. The reaction was started with the addition of $1 \mathrm{~mL}$ of the enzyme diluted $1: 1000$ in the appropriate $0.2 \mathrm{M}$ buffer (citratephosphate $\mathrm{pH}$ 3-6; phosphate $\mathrm{pH} 7-8$; carbonate-bicarbonate $\mathrm{pH}$ 9-11) combined with $1 \mathrm{~mL}$ of $0.5 \mathrm{mM}$ substrate solution (ABTS, DMP or catechol) in a quartz cuvette (final enzyme concentration of $9 \mathrm{mg} \mathrm{mL}^{-1}$ in a $2 \mathrm{~mL}$ volume). The spectrophotometer was zeroed with buffer, the appropriate amount of polymer $(0,1,3$, $5 \%$ ) and the substrate without enzyme $[46,47]$. Substrate oxidation was monitored by measuring the absorbance at $420 \mathrm{~nm}$ for ABTS $\left(\varepsilon=36,000 \mathrm{M}^{-1} \mathrm{~cm}^{-1}\right), 468 \mathrm{~nm}$ for DMP $\left(\varepsilon=49,600 \mathrm{M}^{-1} \mathrm{~cm}^{-1}\right)$, and $450 \mathrm{~nm}$ for catechol $\left(\varepsilon=2211 \mathrm{M}^{-1} \mathrm{~cm}^{-1}\right)$, at the appropriate dilution factor (1:30000 ABTS, 1:60000 DMP and 1:1000 catechol). The catalytic activity was determined by measuring the slope of the initial linear portion of the kinetic curve. One unit (U) of enzyme activity was defined as the amount of enzyme required to oxidize $1 \mu \mathrm{mol}$ of used substrate. Lac activities were expressed in

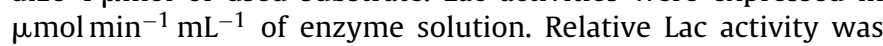
expressed as the ratio between the activity at a given time and the initial activity. All activities were reported as average \pm SD of three independent measurements.

\subsection{Enzymatic stability}

Free Lac stability at different pHs (2-9, using different buffers: citrate-phosphate $\mathrm{pH}$ 3-6; phosphate $\mathrm{pH}$ 7-8; carbonatebicarbonate $\mathrm{pH} 9-11)$ and temperatures $\left(20-70^{\circ} \mathrm{C}\right.$ measured every $10^{\circ} \mathrm{C}$ ) was determined using ABTS, DMP and catechol as substrates. Thermal stability in function of time for the free enzyme was investigated by incubating Lac in ABTS ( $\mathrm{pH} 3)$, DMP ( $\mathrm{pH} \mathrm{6)}$ ) and catechol $(\mathrm{pH} 7)$ for $60 \mathrm{~min}$ at $50^{\circ} \mathrm{C}(\mathrm{pH}$ and temperature pre-established as optimal). Lac thermal stability in function of time in the presence of bare AgNPs, polymer or polymer-stabilized AgNPs was measured in DMP ( $\mathrm{pH} 6$ ) at $50^{\circ} \mathrm{C}$ for 13 days. The solutions were kept in an oven at $50^{\circ} \mathrm{C}$ and the activity measured each day at the same temperature. Enzymatic activity was measured following the method already described in the previous chapter. Data were reported as average \pm SD of three independent measurements.

\section{Results and discussion}

\subsection{Bare AgNPs characterization}

The size distribution and the colloidal dispersion of the AgNPs is determined by the rate of NPs nucleation, subsequent growth and aggregation. Fig. 1A shows the UV-vis spectra of the bare AgNPs. The very distinct and broad peak detected at $412 \mathrm{~nm}$ puts the range of NPs sizes between 30 and $80 \mathrm{~nm}$ and suggests a high polydispersity of the AgNPs [10,48]. DLS spectra (Fig. S1 in the Supporting information) corroborate these data. It estimates the average AgNPs size at $\approx 54 \mathrm{~nm}$ and the polydispersity index at 0.3 , indicating a multimodal distribution [4]. The zeta potential $(\zeta)$ of the AgNPs, which gives a suggestion of the potential stability of the colloid, was determined at $-30 \mathrm{mV}$ and, thus, considered relatively stable. Indeed, if the particles' $\zeta$ values are more positive than $+30 \mathrm{mV}$ or more negative than $-30 \mathrm{mV}$ the colloids are considered stable [49]. Also, it indicates the AgNPs relative stability in the dispersion to result 

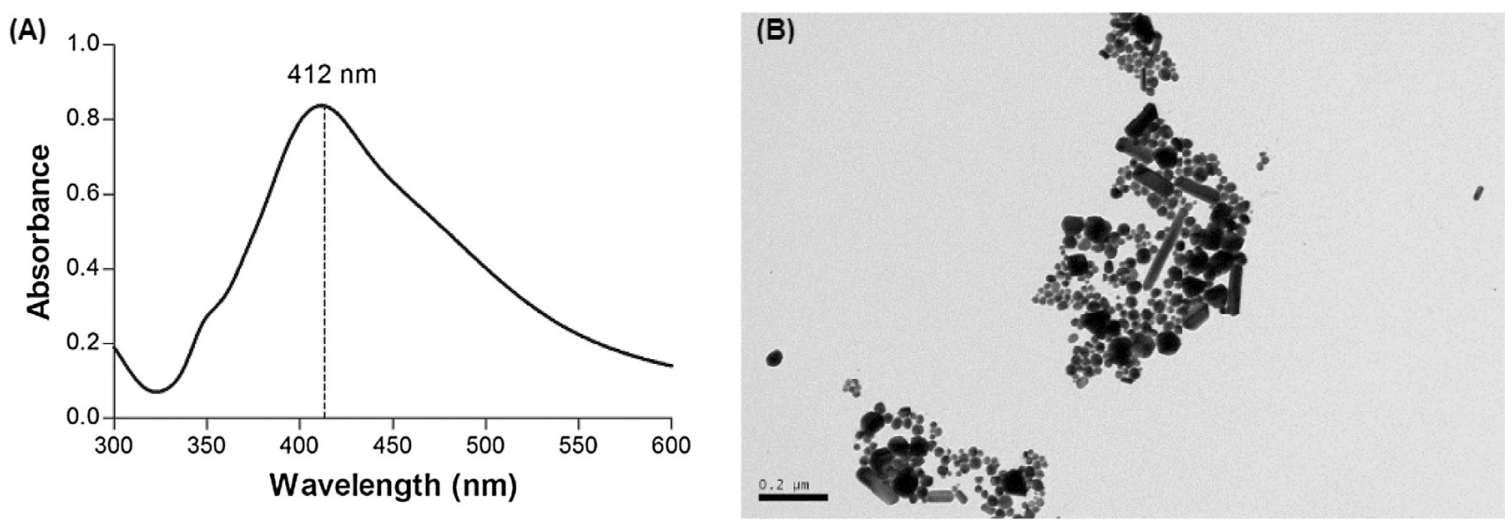

Fig. 1. (A) UV-vis spectra of AgNPs colloidal suspension with dilution factor of 8 (D8x). (B) TEM micrograph of the AgNPs (scale $200 \mathrm{~nm}$ ).

from the electric repulsion of the negative charge of the citrate ions adsorbed on the NPs surface [50].

The TEM image from Fig. 1B shows two families of spherical AgNPs, one formed of small-sized NPs, $\approx 30 \mathrm{~nm}(\approx 85 \%)$, and another formed of larger-sized NPs, $\approx 80 \mathrm{~nm}(\approx 12 \%)$. A third, very little family of rod-shaped AgNPs ranging $910 \mathrm{~nm}(\approx 3 \%)$ was also detected. DLS spectra (Fig. S1 in the Supporting information) corroborate these data. The average diameter calculated by TEM was determined at $34.5 \pm 30.1 \mathrm{~nm}$, demonstrating the high polydispersity of the colloidal AgNPs dispersion. The size distribution of colloidal dispersion of solid particles is determined by the ratio between the rates of nucleation of the solid cores, their subsequent growth, and aggregation. As the reagents initial concentrations were elevated, a considerable number of nuclei were quickly generated, consuming the metallic specimens in the system and resulting in the formation of small NPs, with relative uniform size distribution [51]. Yet, a wide distribution of particle size and shapes, from spheres and cubes to rods and polygons are also observed. This feature is typical for silver colloids prepared by citrate reduction using weak reducing agents, like trisodium citrate $[10,52]$.

\subsection{Polymer-stabilized AgNPs characterization}

To obtain highly stable NPs, with small diameters and uniformity of shape, the AgNPs were synthesized with PEG, PVA and chitosan at different Mw and concentrations. These polymers were used as stabilizing agents because of their polymerization degree and chain length, which is known to protect the NPs from aggregating $[53,54]$. The level of interference of the polymers on the AgNPs adsorption spectra was taken into consideration by using the respective PEG and PVA Mw and concentration as background during UV-vis measurements. Chitosan was excluded from UV-vis testing since its high viscosity made the reading unfeasible.

Adsorption peaks were detected at $\approx 420 \mathrm{~nm}$, indicating the formation of AgNPs both in the presence of PEG and PVA (Fig. 2). Data shows a clear interference of the polymers on the position of the peaks, which have been shifted from the original $412 \mathrm{~nm}$ (bare AgNPs), but more importantly in their intensity. In some cases, namely PVA Mw 85,000, no peaks were detected. The complete disappearance of the AgNPs characteristic peaks is an indicator of the fully aggregated state in which the PVA-AgNPs can be found. Equal observations were made by Kvítek et al. [4]. TEM captures in Fig. 3 confirm this statement.

The DLS and $\zeta$ of the polymer-stabilized AgNPs were not obtained due to the high viscosity and scattering effect of the polymer solution, which interfered with the reading. Instead, TEM was used to analyse the NPs size and shape. For most cases, the association of the AgNPs with PEG or PVA reduced the NPs heterogeneity
Table 1

Average diameter ( $\pm \mathrm{SD}, \mathrm{n}=$ number of NPs in 3 images/condition) of the AgNPs synthesized with PEG and PVA at different $\mathrm{Mw}$ and concentration of $5 \% \mathrm{~m} / \mathrm{v}$.

\begin{tabular}{ll}
\hline Polymer & Average Diameter $\pm \mathrm{SD}(\mathrm{nm})$ \\
\hline AgNPs (Control) & $34.5 \pm 30.1$ \\
PEG Mw 1500 & $25.9 \pm 6.2$ \\
PEG Mw 10,000 & $21.5 \pm 5.1$ \\
PVA Mw 9000 & $21.6 \pm 4.6$ \\
PVA Mw 13,000 & $22.3 \pm 4.6$ \\
PVA Mw 31,000 & $18.8 \pm 2.7$
\end{tabular}

both in size and shape, as expected [16]. The polymers surround the NPs (light grey area in turn of the NPs darker spot, very clear in the first image of Fig. 3), protecting and conferring the NPs the ability to be recognized individually. Fig. 3 shows many of the PEG- and PVA-AgNPs to be monodispersed and to display a spherical-like morphology; rod-shaped NPs are hardly observed. Within these groups, the average size and particularly the polydispersity were reduced when compared to the bare AgNPs (Table 1). Generally, high Mw led to the formation of more uniformly shaped NPs with smaller sizes. It has been shown that polymers with larger number of functional groups have the ability to increase the interactions with $\mathrm{Ag}^{+}$during nucleation. As more binding sites are provided for $\operatorname{Ag}(0)$ atoms to aggregate during reduction, a stronger physical barrier of polymeric chains surrounding the AgNPs is generated. This prevents uncontrolled aggregation and leads to the formation of monodispersed AgNPs [55]. Contradicting this notion are the results from PVA Mw 85,000. Here, aggregates were very frequent. As the Mw increases so does the viscosity of the solution. As a result, the AgNPs become entrapped within the polymeric matrix and are most difficult to identify individually. The same was observed for chitosan $800 \mathrm{Cps}$ and $1600 \mathrm{Cps}$, also a very viscous polymer.

Differences in concentration between equal Mw polymers were neglected from this analysis, since they were found not significant. Only the highest concentrations tested were taken into consideration.

\subsection{Lac activity and stability}

Characterizing the Lac kinetics as function of $\mathrm{pH}$, temperature and substrate provides important information about the enzyme stability with time and its saturation point, which are crucial to predict its behavior. Lac was diluted in appropriate buffers at 1:30,000 for ABTS, 1:60,000 for DMP and 1:1000 for catechol substrates, and its optimal relative and specific activity was established. According to the collected data (Fig. 4), Lac displays optimal activity at $\mathrm{pH} 3$ in ABTS, pH 6 in DMP and pH 7 in catechol. Its specific activity was the highest in ABTS and the lowest in catechol [27]. The 

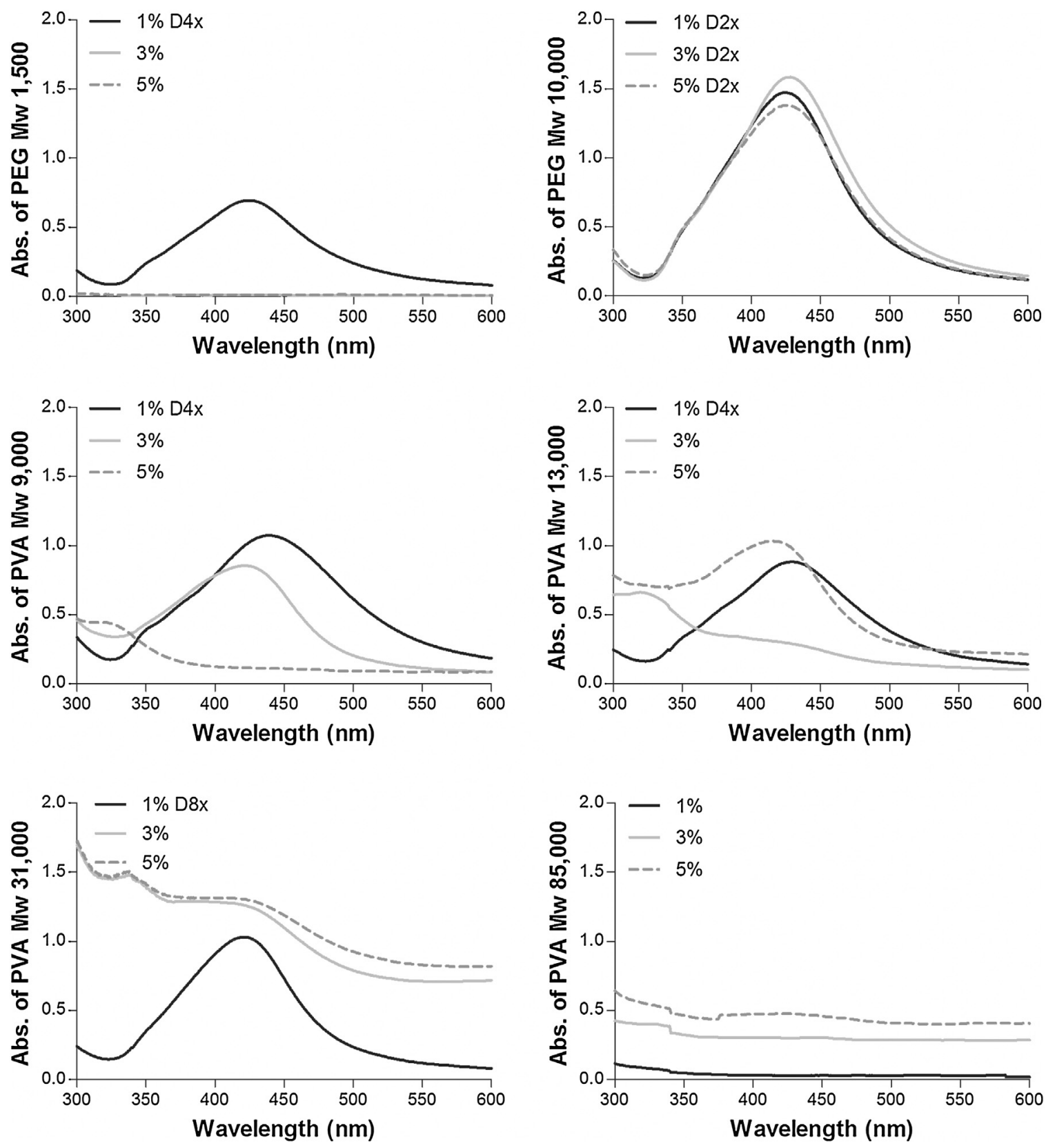

Fig. 2. UV-vis spectra of PEG- and PVA-AgNPs with respective dilution factor (Dnx) applied per concentration.

same was observed during temperature testing (Fig. 5A). Once the optimum $\mathrm{pH}$ for each substrate was established, the kinetics of the enzyme was tested against a range of temperatures, from $20^{\circ} \mathrm{C}$ to $70^{\circ} \mathrm{C}$. As expected, at low temperatures $\left(20^{\circ} \mathrm{C}\right)$ the activity was the slowest since there is a break in the kinetic energy of the molecules in the system [56]. The enzymatic activity increases rapidly as the temperature rises to $\approx 50^{\circ} \mathrm{C}$. After this point, as the risk of denaturation increases, the enzymatic activity decreases significantly. Indeed, after a certain temperature, which for Lac is close to $60^{\circ} \mathrm{C}$ [57], enzymes lose their native structure or conformational integrity and irreversible losses in function are likely to occur [58]. The optimal temperature for the three substrates was established at $50^{\circ} \mathrm{C}$.

The stability of the enzyme Lac was followed for $1 \mathrm{~h}$ at $50^{\circ} \mathrm{C}$, with data being collected every $10 \mathrm{~min}$ (Fig. 5C). The ABTS substrate was the one promoting the highest enzymatic activity in the very first moments. However, its stability was compromised very quickly ( $10 \mathrm{~min}$ ), becoming inactive after $1 \mathrm{~h}$. This happens because Lac oxidizes ABTS to form $\mathrm{ABTS}^{+}$and $\mathrm{ABTS}^{++}$. Lac is quite stable in the presence of $\mathrm{ABTS}^{+}$; however, the divalent cations destabilize the enzyme with time as they generate conditions unsuited to its performance [59]. Although catechol was the substrate with the highest stability after $1 \mathrm{~h}$ testing, DMP was the selected substrate because of its similarly good stability with time and higher specific activity compared to catechol (Figs. 4 and 5).

\subsection{Lac activity and stability in DMP on polymer-stabilized AgNPs}

The process of immobilizing enzymes or proteins on NPs is known to alter their conformation and ionization/dissociation states [60]. By using polymers as stabilizing agents, random intra and intermolecular cross-links are generated with these molecules providing great stability during immobilization [61]. 


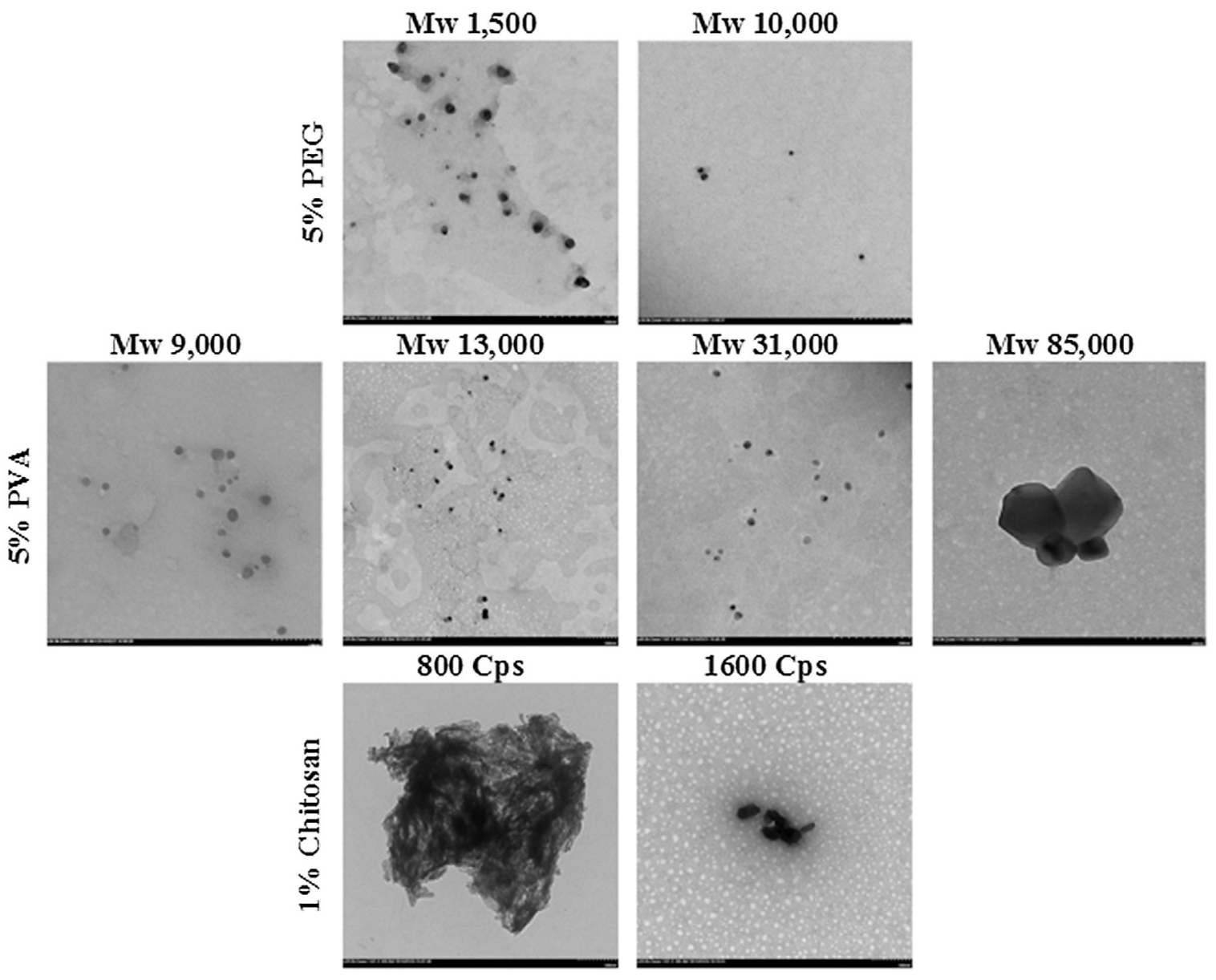

Fig. 3. TEM micrographies of the PEG-, PVA- and chitosan-AgNPs at 5\% concentration (scale $100 \mathrm{~nm}$ for PVA Mw 9000 and $200 \mathrm{~nm}$ for all other samples).
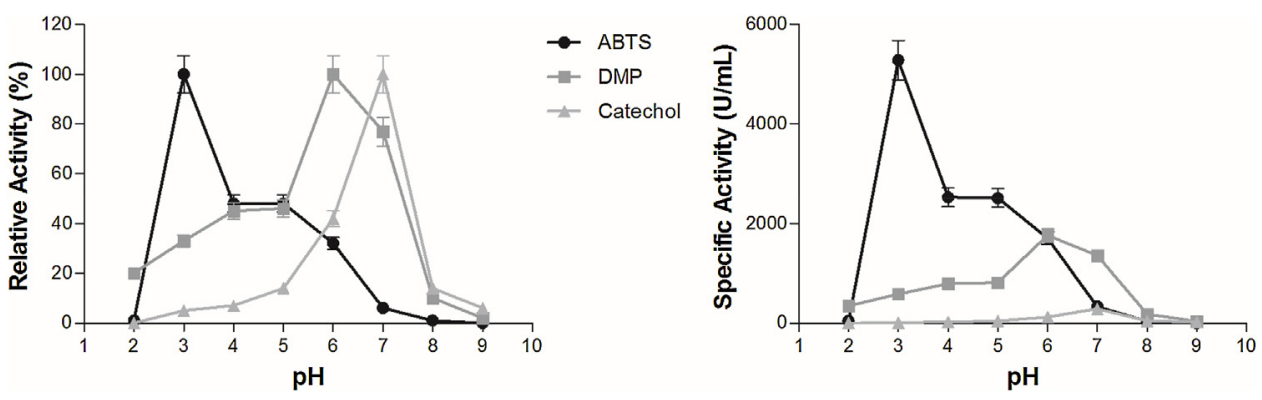

Fig. 4. Lac relative and specific activity as function of $\mathrm{pH}$ in $\mathrm{ABTS}, \mathrm{DMP}$ and catechol $(\mathrm{SD}, \mathrm{n}=3)$.

Lac and polymer-stabilized AgNPs were incubated at $50^{\circ} \mathrm{C}$ and the enzyme activity was measured until it was inexistent or residual, using DMP as substrate (Fig. 6). The maximum incubation period was established at 13 days, at which point most tested groups ceased their activity. After day 1, all polymer-stabilized AgNPs groups exhibited specific activity, however lower than the controls (Fig. 6A). The highest activity was registered by $1 \%$ PVA Mw 9000 and Mw 31,000, 3\% PVA Mw 13,000 and 5\% PEG Mw 1500. After 3 days of incubations, Lac lost its activity in most polymer-stabilized AgNPs with only 1\% PVA 85,000 and 3\% PVA Mw 9000 registering activity above $100 \mathrm{U} / \mathrm{mL}$. Past this point, the LacAgNPs control group became inactive, while the free Lac remained active until day 9, however at a much lower level. At the end of 6 days both PVA Mw 9000 and 31,000 lost their activity completely, which occurred at day 10 for PEG Mw 10,000 and chitosan 1600 Cps.
In theory, it would be expected PEG to repel Lac due to its antifouling nature. Yet, the interaction was successful. Recent studies have shown that PEG binds to proteins under certain conditions [62]. Protein-PEG interactions in solution display a temperaturedependent behaviour, which becomes more favourable as the temperature rises above $37^{\circ} \mathrm{C}$. The temperature used to synthesize the AgNPs was $100^{\circ} \mathrm{C}$ and all the Lac activity measurements were conducted at $50^{\circ} \mathrm{C}$. PEG chain segments can also adopt multiple configurations and different conformers while interacting with water molecules and NPs. Hence, PEG interactions with water, protein and NPs cannot be reduced to a simple polymer theory, such as the excluded volume, since there is no theoretical model that adequately predicts the behaviour of PEG [63].

A particular kinetics of enzymatic activity was observed with PEG Mw 1500 and Mw 10,000 and PVA Mw 13,000 and Mw 85,000: a slow decrease in activity was followed by a sudden increase, 

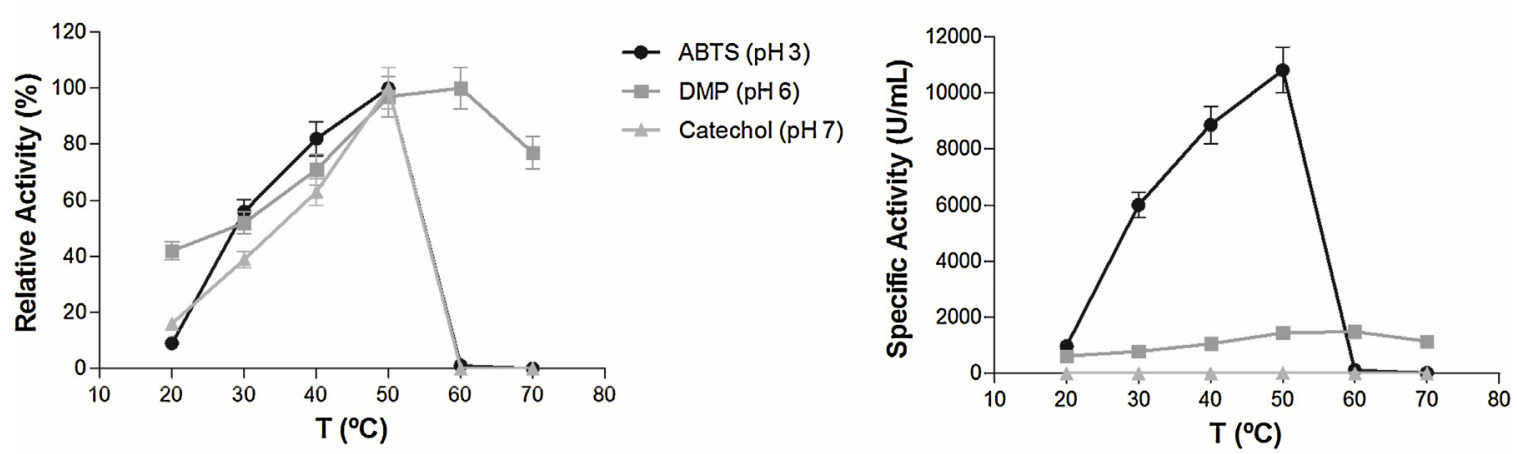

(B)

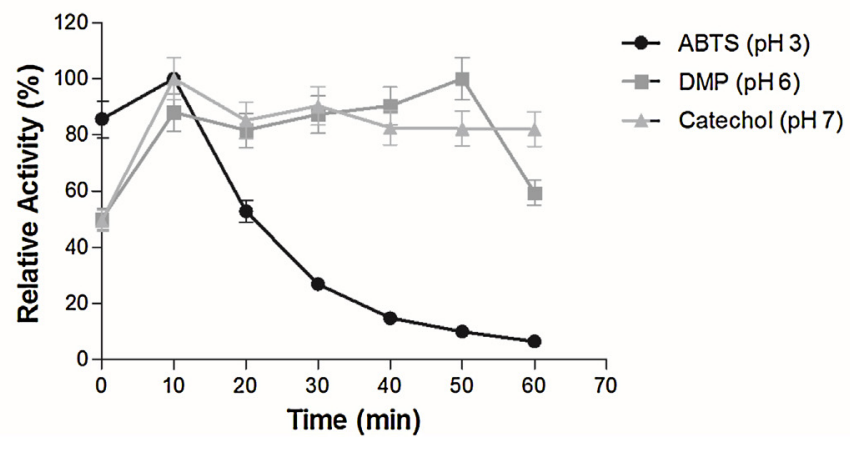

Fig. 5. (A) Lac relative and specific activity as function of temperature and (B) Lac stability as function of time, in ABTS, DMP and catechol (SD, $n=3$ ).

which was finally succeeded by an even quicker drop. This phenomenon is explained by the polymers water-soluble properties. As the polymer loses its stability in water, the enzyme immobilized detaches from the polymeric micelle and, consequently, an increase in its specific activity is detected by the system. However, because the enzyme loses its polymeric protection, its activity cannot stand and decays very quickly [64]. In most groups, at a polymer concentration of $5 \%$, the Lac activity is lost (or becomes residual) at the end of 3 days. The amount of polymer interacting with the enzyme prevents its access by the DMP substrate. Lac revealed great stability in the presence of PVA Mw 13,000, particularly at $1 \%$ concentration, expressing activity even after 13 days (up to 18 days, data not shown). For most polymers, a balance between the highest and the lowest concentration, $3 \%$, was seen to be the most effective in promoting Lac activity.

In contrast with the other polymers, chitosan instigated very little enzymatic activity. With the exception of $1 \%$ chitosan at 800 $\mathrm{Cps}$, the rest were barely noticed. Chitosan being a polyelectrolyte of positive charge is capable of destabilizing the enzyme activity and significantly influence the immobilization process. In its linear polyglucosamine chains of high Mw, chitosan possesses reactive amino and hydroxyl groups amenable of chemical modifications. Its singular alkaline properties, which confer a positive charge, allow chitosan to efficiently interact with polyanionic compounds like proteins [65]. Thus, by enabling many ionic interactions, chitosan restricts the mass transfer between the substrate and Lac. Despite the clear interference of chitosan in the stability and activity of the enzyme, the repulsion between the AgNPs and the chitosan positive charges allows for some mobility. This may be responsible for the residual activity manifested after day 3 in the presence of AgNPs but not in its absence (Fig. 6C).

In the absence of AgNPs (Fig. 6C), Lac activity only lasted 3 days regardless the polymer in use and concentration tested.
The kinetics of activity was also similar, starting high at day 1 and continuously decreasing until day 3 . These results attest to the efficacy of the polymer-stabilized AgNPs to promote Lac activity and stability throughout time. Data suggests that the enzyme becomes protected once in contact with the polymer-stabilized AgNPs, which guarantees its stability. Lac-AgNPs or free Lac (controls) showed low stabilities [66,67]. Although extra polymer is present in the solution and can interact with the NPs or enzyme, its protection is not as effective as when the polymer is conjugated with AgNPs. The polymers are not capable of stabilizing the enzyme by non-specific interactions [68]. It is necessary the formation of a stable hydrogel structure to which the enzyme binds strongly, avoiding diffusion into the surrounding media, acquiring protection from denaturing factors and, simultaneously, obtaining access to the active sites, thus potentially enhancing its operational stability [69]. Under these premises, it is likely the PVA or PEG to regulate not only the NPs size and shape but as well to limit the deleterious effect of the $\mathrm{Ag}^{+}$release on the enzyme structure. Data from the control groups (Fig. 6A), show that Lac activity only lasts 3 days in the presence of AgNPs, while in its absence, free Lac, remains in action for another six days, however at a much lower level $(\approx 130 \mathrm{U} / \mathrm{mL})$, and only ceases at day $9(\approx 5.1 \mathrm{U} / \mathrm{mL})$. The enhanced stability of AgNPs dispersions provided by water-soluble polymers is usually based on the steric repulsion of the polymers that are immediately adsorbed at the phase interphase. The balance between the attractive and the repulsive forces is strongly dependent on the thickness of the adsorbed layer, which, on its turn, is function of the chain length and adsorption mode of the used polymer [70]. This could explain the increase in Lac activity manifested by the hybrid AgNPs-polymer-Lac with time. The decrease in diameter of the polymeric coating surrounding the NPs may favor the detachment and diffusion of the enzyme in solution, until the protection offered is too weak to prevent the $\mathrm{Ag}^{+}$from releasing and dena- 


\section{(A) Control}

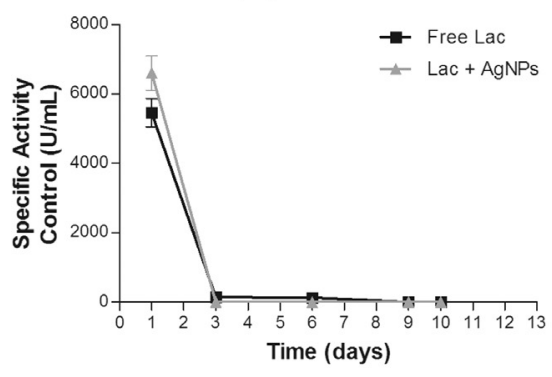

(B) With AgNPs
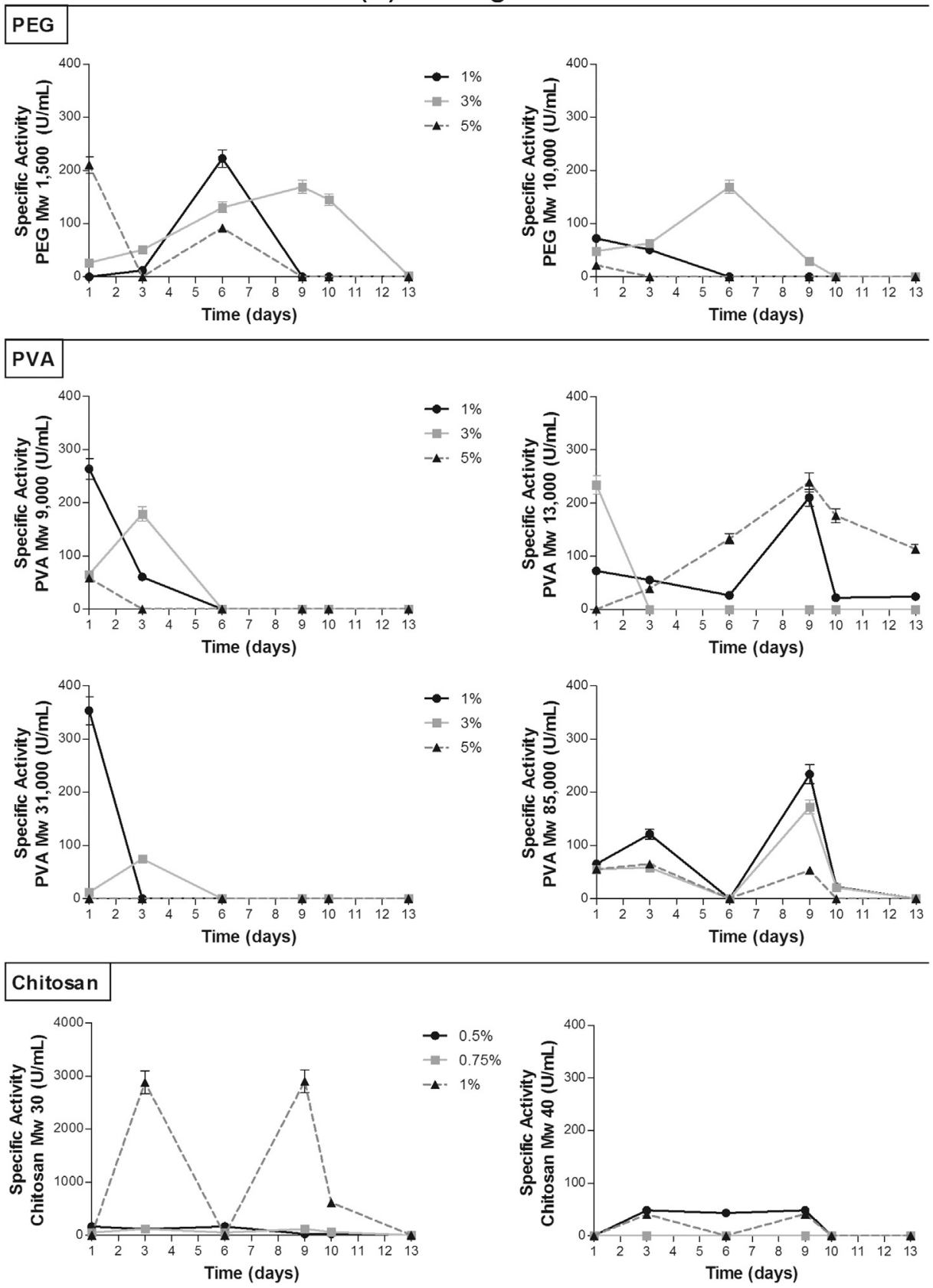

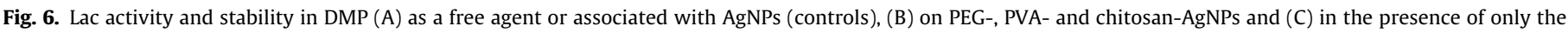
polymers PEG, PVA and chitosan (without AgNPs) (SD, $n=3$ ). 
(C) Without AgNPs
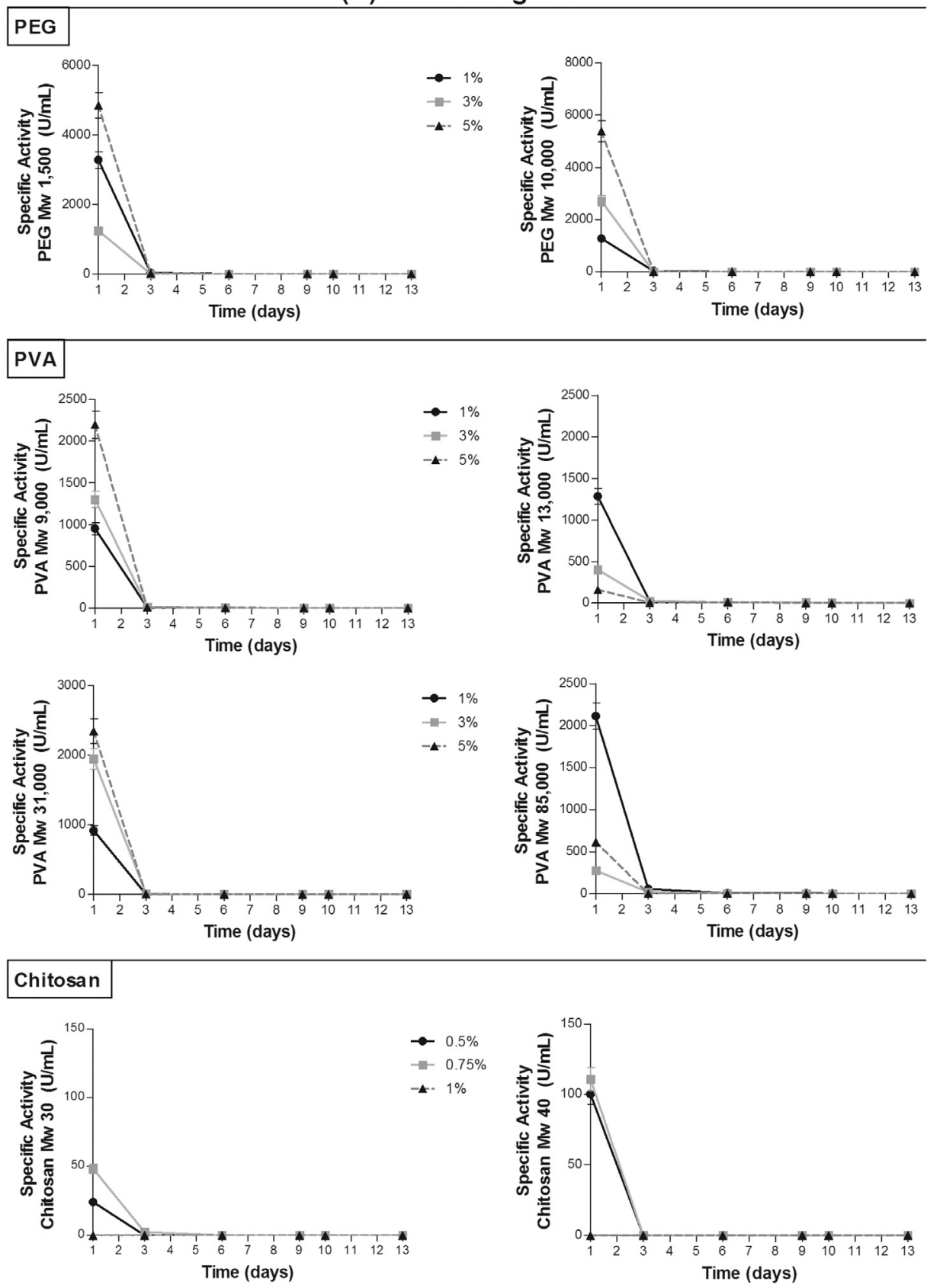

Fig. 6. (Continued)

turing the enzyme [66]. This behavior not only reveals a synergistic effect on the Lac stability but also allows a time-dependent action of the antimicrobials in which, first the Lac and second, after enzyme denaturation, the $\mathrm{Ag}^{+}$act to reduce the risk of resistance-associated mutations.

A quick analysis of the Lac activity on polymer-stabilized AgNPs in the presence of ABTS ( $\mathrm{pH} 3$ ) substrate was also conducted (Fig. S2 in the Supporting information). Data collected revealed very little activity throughout time regardless the polymer used as protecting agent. The differences in optimal pH between ABTS and the phenolic substrate DMP reflect the difference in Lac oxidation mechanism for each substrate that may affect the stability of complex systems like those in study [71]. Even so, in the absence of AgNPs, Lac demonstrated greater activity than with DMP. This is explained by the fact that the oxidation of ABTS to the stable cation radi- cal does not involve protons, and thus possesses a redox potential independent of $\mathrm{pH}$. On the other hand, Lac is greatly affected by the difference in $\mathrm{pH}$ due to the contribution of the $\mathrm{OH}^{-}$inhibition. Another explanation can be attributed to the enhanced $\mathrm{Ag}^{+}$solubility and high degree of aggregation of the AgNPs in presence of dissolved $\mathrm{O}_{2}$ at low $\mathrm{pH}$ values [72,73].

\section{Conclusions}

Synthesis of AgNPs by citrate reduction method using polymeric reducing agents, PEG, PVA and chitosan, resulted in tunable AgNPs sizes and shapes. As protecting agents, PEG and PVA promoted the formation of spherical uniformly-shaped, small-sized, monodispersed NPs. With the exception of PVA Mw 85,000, which generated aggregates (high viscosity), high Mw polymers were established as 
most effective in producing small-sized NPs. Chitosan's viscosity impaired this phenomenon.

Lac activity and stability were stimulated in the presence of DMP. A decrease in the enzymatic activity was detected once Lac was immobilized on the PEG- and PVA-AgNPs. This, however, was promptly disregarded as the polymer-stabilized AgNPs increased the enzyme stability over time and were capable of maintaining its activity up to 13 days. At this point, the polymers lost their stability in water and the enzyme lost its protection. At high polymer concentrations (5\%), however, Lac activity was lost after 3 days since the polymer prevented the access by DMP. By enabling many ionic interactions, chitosan restricted the mass transfer between Lac and substrate and, thus, promoted very little enzymatic activity.

Generally, the efficacy of the polymer-stabilized AgNPs in promoting Lac stability with time was established. By implementing this strategy, the limitations of using both AgNPs and enzymes as therapeutic agents in the fight against microbial organisms and biofilm formation could be overcome, and a new antimicrobial synergistic approach with promising biomedical applications uncovered. Moreover, since the release of the $\mathrm{Lac}$ and $\mathrm{Ag}^{+}$antimicrobial effects are different in time, this hybrid allows a superior antimicrobial effect reducing the risk of the appearance of drug resistance-associated mutations.

At this moment, microbiology experiments using gram-positive and gram-negative bacteria are at course with the goal of proofing this concept. Different methods are being used to establish the antimicrobial synergistic effect of Lac, polymer stabilizers and AgNPs, and its cytotoxic profile is being outlined recurring to human fibroblasts. In a near future, a report of the data acquired will be published.

\section{Competing financial interests}

The authors declare no competing financial interest.

\section{Acknowledgements}

This work was funded by Portuguese Foundation for Science and TechnologyFCT/MCTES (PIDDAC) and co-financed by European funds (FEDER) through the PT2020 program, research projectMERA-NET/0006/2014. A. Zille and H. P. Felgueiras also acknowledge funding from FCT within the scope of the project POCI-01-0145FEDER-007136 and UID/CTM/00264.

\section{Appendix A. Supplementary data}

Supplementary data associated with this article can be found, in the online version, at http://dx.doi.org/10.1016/j.colsurfb.2017.03. 023.

\section{References}

[1] R. Ghosh Chaudhuri, S. Paria, Core/shell nanoparticles: classes, properties, synthesis mechanisms, characterization, and applications, Chem. Rev. 112 (2011) 2373-2433.

[2] A.H. Lu, E.e.L. Salabas, F. Schüth, Magnetic nanoparticles: synthesis, protection, functionalization, and application, Angew. Chem. Int. Ed. 46 (2007) 1222-1244.

[3] Q.H. Tran, A.-T. Le, Silver nanoparticles: synthesis, properties, toxicology, applications and perspectives, Adv. Nat. Sci. Nanosci. Nanotechnol. 4 (2013) 033001

[4] L. Kvitek, A. Panáček, J. Soukupova, M. Kolar, R. Vecerova, R. Prucek, M. Holecova, R. Zboril, Effect of surfactants and polymers on stability and antibacterial activity of silver nanoparticles (NPs), J. Phys. Chem. C 112 (2008) 5825-5834.

[5] A. Ivask, A. ElBadawy, C. Kaweeteerawat, D. Boren, H. Fischer, Z. Ji, C.H. Chang, R. Liu, T. Tolaymat, D. Telesca, J.I. Zink, Y. Cohen, P.A. Holden, H.A. Godwin, Toxicity mechanisms in escherichia coli vary for silver nanoparticles and differ from ionic silver, ACS Nano 8 (2014) 374-386.
[6] J.R. Morones, J.L. Elechiguerra, A. Camacho, K. Holt, J.B. Kouri, J.T. Ramírez, M.J. Yacaman, The bactericidal effect of silver nanoparticles, Nanotechnology 16 (2005) 2346-2353.

[7] M. Kostić, N. Radić, B.M. Obradović, S. Dimitrijević, M.M. Kuraica, P. Škundrić, Antimicrobial textile prepared by silver deposition on dielectric barrier discharge treated cotton/polyester fabric, Chem. Ind. Chem. Eng. Q./CICEQ 14 (2008) 219-221.

[8] G. Martinez-Castanon, N. Nino-Martinez, F. Martinez-Gutierrez, J. Martinez-Mendoza, F. Ruiz, Synthesis and antibacterial activity of silver nanoparticles with different sizes, J. Nanopart. Res. 10 (2008) 1343-1348.

[9] S. Pal, Y.K. Tak, J.M. Song, Does the antibacterial activity of silver nanoparticles depend on the shape of the nanoparticle? A study of the gram-negative bacterium Escherichia coli, Appl. Environ. Microbiol. 73 (2007) 1712-1720.

[10] S. Agnihotri, S. Mukherji, S. Mukherji, Size-controlled silver nanoparticles synthesized over the range 5-100 nm using the same protocol and their antibacterial efficacy, RSC Adv. 4 (2014) 3974-3983.

[11] B. Khodashenas, H.R. Ghorbani, Synthesis of silver nanoparticles with different shapes, Arab. J. Chem. (2015), http://dx.doi.org/10.1016/j.arabjc.2014.12.014.

[12] S. Iravani, H. Korbekandi, S. Mirmohammadi, B. Zolfaghari, Synthesis of silver nanoparticles: chemical, physical and biological methods, Res. Pharm. Sci. 9 (2014) 385-406

[13] D. Steinigeweg, S. Schlücker, Monodispersity and size control in the synthesis of 20-100 nm quasi-spherical silver nanoparticles by citrate and ascorbic acid reduction in glycerol-water mixtures, Chem. Commun. 48 (2012) 8682-8684

[14] C. Luo, Y. Zhang, X. Zeng, Y. Zeng, Y. Wang, The role of poly (ethylene glycol) in the formation of silver nanoparticles, J. Colloid Interface Sci. 288 (2005) 444-448.

[15] Z. Mbhele, M. Salemane, C. Van Sittert, J. Nedeljkovic, V. Djokovic, A. Luyt, Fabrication and characterization of silver-polyvinyl alcohol nanocomposites, Chem. Mater. 15 (2003) 5019-5024.

[16] J.-J. Lin, W.-C. Lin, R.-X. Dong, S.-h. Hsu, The cellular responses and antibacterial activities of silver nanoparticles stabilized by different polymers, Nanotechnology 23 (2012) 065102.

[17] H. Huang, Q. Yuan, X. Yang, Preparation and characterization of metal-chitosan nanocomposites, Colloids Surf. B: Biointerfaces 39 (2004) 31-37.

[18] D. Long, G. Wu, S. Chen, Preparation of oligochitosan stabilized silver nanoparticles by gamma irradiation, Radiat. Phys. Chem. 76 (2007) 1126-1131.

[19] R.A. Sperling, W.J. Parak, Surface modification, functionalization and bioconjugation of colloidal inorganic nanoparticles, Philos. Trans. R. Soc. A: Math. Phys. Eng. Sci. 368 (2010) 1333-1383.

[20] K.S. Kumar, V.B. Kumar, P. Paik, Recent advancement in functional core-shell nanoparticles of polymers: synthesis, physical properties, and applications in medical biotechnology, J. Nanoparticles 2013 (2013) 1-24.

[21] R. de Lima, A.B. Seabra, N. Durán, Silver nanoparticles: a brief review of cytotoxicity and genotoxicity of chemically and biogenically synthesized nanoparticles, J. Appl. Toxicol. 32 (2012) 867-879.

[22] K.M.G. Hossain, M.D. González, G.R. Lozano, T. Tzanov, Multifunctional modification of wool using an enzymatic process in aqueous-organic media, J. Biotechnol. 141 (2009) 58-63.

[23] N. Grover, C.Z. Dinu, R.S. Kane, J.S. Dordick, Enzyme-based formulations for decontamination: current state and perspectives, Appl. Microbiol. Biotechnol. 97 (2013) 3293-3300.

[24] J. Kulys, I. Bratkovskaja, R. Vidziunaite, Laccase-catalysed iodide oxidation in presence of methyl syringate, Biotechnol. Bioeng. 92 (2005) 124-128.

[25] A. Othman, A. Elshafei, M. Hassan, B. Haroun, M. Elsayed, A. Farrag, Purification, biochemical characterization and applications of pleurotus ostreatus ARC280 laccase, Br. Microbiol. Res. J. 4 (2014) 1418-1439.

[26] S. Christie, S. Shanmugam, Analysis of fungal cultures isolated from Anamalai Hills for laccase enzyme production effect on dye decolorization, antimicrobial activity, Int. J. Plant Anim. Environ. Sci. 2 (2012) 143-148.

[27] L.M.P. Sampaio, J. Padrão, J. Faria, J.P. Silva, C.J. Silva, F. Dourado, A. Zille, Laccase immobilization on bacterial nanocellulose membranes: antimicrobial, kinetic and stability properties, Carbohyd. Polym. 145 (2016) 1-12.

[28] A.A. Vertegel, V. Reukov, V. Maximov, Enzyme-Nanoparticle conjugates for biomedical applications, in: S.D. Minter (Ed.), Enzyme Stabilization and Immobilization: Methods and Protocols, Springer, 2011, pp. 165-182.

[29] S. Guo, H. Li, J. Liu, Y. Yang, W. Kong, S. Qiao, H. Huang, Y. Liu, Z. Kang, Visible-Light-Induced effects of Au nanoparticle on laccase catalytic activity, ACS Appl. Mater. Interfaces 7 (2015) 20937-20944.

[30] Z. Khani, C. Jolivalt, M. Cretin, S. Tingry, C. Innocent, Alginate/carbon composite beads for laccase and glucose oxidase encapsulation: application in biofuel cell technology, Biotechnol. Lett. 28 (2006) 1779-1786.

[31] G. Bayramoglu, M. Yilmaz, M.Y. Arica, Preparation and characterization of epoxy-functionalized magnetic chitosan beads: laccase immobilized for degradation of reactive dyes, Bioprocess Biosyst. Eng. 33 (2010) 439-448.

[32] D. Spinelli, E. Fatarella, A. Di Michele, R. Pogni, Immobilization of fungal (Trametes versicolor) laccase onto Amberlite IR-120 H beads: optimization and characterization, Process Biochem. 48 (2013) 218-223.

[33] S.K. Patel, V.C. Kalia, J.-H. Choi, J.-R. Haw, I.-W. Kim, J.K. Lee, Immobilization of laccase on $\mathrm{SiO} 2$ nanocarriers improves its stability and reusability, J. Microbiol. Biotechnol. 24 (2014) 639-647.

[34] F. Wang, C. Guo, H.Z. Liu, C.Z. Liu, Immobilization of Pycnoporus sanguineus laccase by metal affinity adsorption on magnetic chelator particles, J. Chem. Technol. Biotechnol. 83 (2008) 97-104. 
[35] H. Fang, J. Huang, L. Ding, M. Li, Z. Chen, Preparation of magnetic chitosan nanoparticles and immobilization of laccase, J. Wuhan Univ. Technol.-Mater. Sci. Ed. 24 (2009) 42-47.

[36] H. Qiu, C. Xu, X. Huang, Y. Ding, Y. Qu, P. Gao, Immobilization of laccase on nanoporous gold: comparative studies on the immobilization strategies and the particle size effects, J. Phys. Chem. C 113 (2009) 2521-2525.

[37] A. Lateef, A.O. Adeeyo, Green synthesis and antibacterial activities of silver nanoparticles using extracellular laccase of, Notulae Scientia Biologicae 7 (2015) 405.

[38] L.M. Sampaio, J. Padrão, J. Faria, J.P. Silva, C.J. Silva, F. Dourado, A. Zille, Laccase immobilization on bacterial nanocellulose membranes: antimicrobial, kinetic and stability properties, Carbohyd. Polym. 145 (2016) 1-12.

[39] C. Sanchez, B. Julián, P. Belleville, M. Popall, Applications of hybrid organic-inorganic nanocomposites, J. Mater. Chem. 15 (2005) 3559-3592.

[40] L. Mei, Z. Lu, X. Zhang, C. Li, Y. Jia, Polymer-Ag nanocomposites with enhanced antimicrobial activity against bacterial infection, ACS Appl. Mater. Interfaces 6 (2014) 15813-15821.

[41] A. Zille, M.M. Fernandes, A. Francesko, T. Tzanov, M. Fernandes, F.R. Oliveira, L. Almeida, T. Amorim, N. Carneiro, M.F. Esteves, A.P. Souto, Size and aging effects on antimicrobial efficiency of silver nanoparticles coated on polyamide fabrics activated by atmospheric DBD plasma, ACS Appl. Mater. Interfaces 7 (2015) 13731-13744

[42] D.M. Eby, H.R. Luckarift, G.R. Johnson, Hybrid antimicrobial enzyme and silver nanoparticle coatings for medical instruments, ACS Appl. Mater. Interfaces 1 (2009) 1553-1560.

[43] L.M.P. Sampaio, J. Padrao, J. Faria, J.P. Silva, C.J. Silva, F. Dourado, A. Zille, Laccase immobilization on bacterial nanocellulose membranes: antimicrobial, kinetic and stability properties, Carbohyd. Polym. 145 (2016) 1-12.

[44] J. Turkevich, P.C. Stevenson, J. Hillier, A study of the nucleation and growth processes in the synthesis of colloidal gold, Discuss. Faraday Soc. 11 (1951) $55-75$.

[45] N.K. Vu, A. Zille, F.R. Oliveira, N. Carneiro, A.P. Souto, Effect of particle size on silver nanoparticle deposition onto dielectric barrier discharge (DBD) plasma functionalized polyamide fabric, Plasma Process. Polym. 10 (2013) 285-296.

[46] I. Eichlerová, J. Šnajdr, P. Baldrian, Laccase activity in soils: considerations for the measurement of enzyme activity, Chemosphere 88 (2012) 1154-1160.

[47] P. Ander, K. Messner, Oxidation of 1-hydroxybenzotriazole by laccase and lignin peroxidase, Biotechnol. Tech. 12 (1998) 191-195.

[48] Y. Xia, N.J. Halas, Shape-controlled synthesis and surface plasmonic properties of metallic nanostructures, MRS Bull. 30 (2005) 338-348.

[49] A. Saeb, A.S. Alshammari, H. Al-Brahim, K.A. Al-Rubeaan, Production of silver nanoparticles with strong and stable antimicrobial activity against highly pathogenic and multidrug resistant bacteria, Sci. World J. (2014) 1-9, ID 704708.

[50] L.V. Stebounova, E. Guio, V.H. Grassian, Silver nanoparticles in simulated biological media: a study of aggregation, sedimentation, and dissolution, J. Nanopart. Res. 13 (2011) 233-244.

[51] S. Magdassi, A. Bassa, Y. Vinetsky, A. Kamyshny, Silver nanoparticles as pigments for water-based ink-jet inks, Chem. Mater. 15 (2003) 2208-2217.

[52] Y. Cao, R. Zheng, X. Ji, H. Liu, R. Xie, W. Yang, Syntheses and characterization of nearly monodispersed, size-tunable silver nanoparticles over a wide size range of 7-200 nm by tannic acid reduction, Langmuir 30 (2014) 3876-3882.

[53] K.-S. Chou, C.-Y. Ren, Synthesis of nanosized silver particles by chemical reduction method, Mater. Chem. Phys. 64 (2000) 241-246.

[54] M. Popa, T. Pradell, D. Crespo, J.M. Calderón-Moreno, Stable silver colloidal dispersions using short chain polyethylene glycol, Coll. Surf. A 303 (2007) 184-190.
[55] M. Hettiarachchi, P. Wickramarachchi, Synthesis of chitosan stabilized silver nanoparticles using gamma ray irradiation and characterization, J. Sci. Univ, Kelaniya Sri Lanka 6 (2011) 65-75.

[56] M.E. Peterson, R.M. Daniel, M.J. Danson, R. Eisenthal, The dependence of enzyme activity on temperature: determination and validation of parameters, Biochem. J. 402 (2007) 331-337.

[57] A. Kunamneni, I. Ghazi, S. Camarero, A. Ballesteros, F.J. Plou, M. Alcalde, Decolorization of synthetic dyes by laccase immobilized on epoxy-activated carriers, Process Biochem. 43 (2008) 169-178.

[58] R.M. Daniel, M. Dines, H.H. Petach, The denaturation and degradation of stable enzymes at high temperatures, Biochem. J 317 (1996) 1-11.

[59] B. Branchi, C. Galli, P. Gentili, Kinetics of oxidation of benzyl alcohols by the dication and radical cation of ABTS. Comparison with laccase-ABTS oxidations: an apparent paradox, Org. Biomol. Chem. 3 (2005) 2604-2614.

[60] E. Akertek, L. Tarhan, Characterization of immobilized catalases and their application in pasteurization of milk with H2O2, Appl. Biochem. Biotechnol. 50 (1995) 291-303.

[61] J. Rogalski, E. Jóźwik, A. Hatakka, A. Leonowicz, Immobilization of laccase from Phlebia radiata on controlled porosity glass, J. Mol. Catal. A: Chem. 95 (1995) 99-108.

[62] N. Efremova, S. Sheth, D. Leckband, Protein-induced changes in poly (ethylene glycol) brushes: molecular weight and temperature dependence, Langmuir 17 (2001) 7628-7636.

[63] S. Sheth, D. Leckband, Measurements of attractive forces between proteins and end-grafted poly (ethylene glycol) chains, Proc. Natl. Acad. Sci. 94 (1997) 8399-8404

[64] A.A. Homaei, R. Sariri, F. Vianello, R. Stevanato, Enzyme immobilization: an update, J. Chem. Biol. 6 (2013) 185-205.

[65] B. Krajewska, Application of chitin-and chitosan-based materials for enzyme immobilizations: a review, Enzyme Microb. Technol. 35 (2004) 126-139.

[66] G.A. Petkova, K. Záruba, P. Žvátora, V. Král, Gold and silver nanoparticles for biomolecule immobilization and enzymatic catalysis, Nanoscale Res. Lett. 7 (2012) $1-10$

[67] A.M. Wang, H. Wang, C. Zhou, Z.Q. Du, S.M. Zhu, S.B. Shen, Ag-induced efficient immobilization of papain on silica spheres, Chin. J. Chem. Eng. 16 (2008) 612-619.

[68] P.V. Iyer, L. Ananthanarayan, Enzyme stability and stabilization-aqueous and non-aqueous environment, Process Biochem. 43 (2008) 1019-1032.

[69] Y. Wang, Y.L. Hsieh, Immobilization of lipase enzyme in polyvinyl alcohol (PVA) nanofibrous membranes, J. Membr. Sci. 309 (2008) 73-81.

[70] L. Kvítek, A. Panáček, J. Soukupová, M. Kolář, R. Večeřová, R. Prucek, M. Holecová, R. Zbořil, Effect of surfactants and polymers on stability and antibacterial activity of silver nanoparticles (NPs), J. Phys. Chem. C 112 (2008) 5825-5834.

[71] H. Chakroun, T. Mechichi, M.J. Martinez, A. Dhouib, S. Sayadi, Purification and characterization of a novel laccase from the ascomycete Trichoderma atroviride: application on bioremediation of phenolic compounds, Process Biochem. 45 (2010) 507-513.

[72] A.M.E. Badawy, T.P. Luxton, R.G. Silva, K.G. Scheckel, M.T. Suidan, T.M. Tolaymat, Impact of environmental conditions ( $\mathrm{pH}$, ionic strength, and electrolyte type) on the surface charge and aggregation of silver nanoparticles suspensions, Environ. Sci. Technol. 44 (2010) 1260-1266.

[73] C. Levard, E.M. Hotze, G.V. Lowry, G.E. Brown, Environmental transformations of silver nanoparticles: impact on stability and toxicity, Environ. Sci. Technol. 46 (2012) 6900-6914. 